\title{
ANÁLISE EM MICROSCOPIA ELETRÔNICA DE VARREDURA DE SUPERFÍCIES RADICULARES ANTES E APÓS RASPAGEM E CONDICIONAMENTO COM ÁCIDO CÍTRICO E EDTA: UM ESTUDO “IN VITRO”
}

\author{
SCANNING ELECTRON MICROSCOPY ANALYSIS ON ROOT SURFACES \\ BEFORE AND AFTER SCALLING AND CITRIC ACID AND EDTA \\ CONDITIONING: AN “IN VITRO” STUDY
}

Fabio Valverde Rodrigues BASTOS NETO

Mestre em Odontologia, área de Periodontia pela Faculdade de Odontologia de Bauru / USP.

Sebastião Luiz Aguiar GREGHI

Doutor em Odontologia, área de Periodontia pela Faculdade de Odontologia de Bauru / USP.

Professor Assistente do Departamento de Prótese da Faculdade de Odontologia de Bauru / USP.

\begin{abstract}
A superfície radicular mais benéfica para a regeneração do periodonto ainda não está estabelecida. Visando uma busca por esta superfície este trabalho utilizou 14 dentes de humanos recém extraídos, seccionados em corpos de prova e tratados com raspagem e condicionamentos com ácido cítrico e EDTA e analisados em microscopia eletrônica de varredura. As superfícies hígidas apresentavam grânulos regulares provenientes de fibras do ligamento periodontal rompidas na exodontia. As superfícies contaminadas apresentavam massas de cálculo aderidas e áreas de reabsorção cementária. Quando raspadas com curetas manuais as superfícies foram cobertas por "smear layer". O condicionamento com ácido cítrico foi eficiente na remoção total do "smear layer", assim como o condicionamento com EDTA gel, e o condicionamento com EDTA líquido não teve efetividade total na sua remoção. Tomando como padrão as superfícies hígidas, conclui-se que os tratamentos que mais se aproximam do ideal são a raspagem e condicionamento com ácido cítrico e EDTA gel sem diferenças entre si.
\end{abstract}

UNITERMOS: Raspagem radicular; Condicionamento ácido; Ácido Cítrico; EDTA.

\section{INTRODUÇÃO}

O principal objetivo da terapia periodontal diz respeito à reparação dos tecidos de suporte, ou seja, osso, ligamento periodontal e cemento radicular comprometidos pela doença periodontal ${ }^{23}$. Para que isto possa ser conseguido, deve-se proporcionar aos tecidos remanescentes condições ideais para sua cicatrização. Segundo Schwartz ${ }^{22}$, para que haja regeneração periodontal, são condições muito importantes aos tecidos: ausência de processos infecciosos agudos; criação e manutenção de um coágulo estável na área; isolamento por tecidos competitivos (atualmente com o uso de membranas - "regeneração tecidual guiada"); criação de uma superfície radicular biologicamente compatível, sem células e/ou produtos químicos bacterianos; e, fisicamente, criação de uma superfície com rugosidade ideal para migração e proliferação celular. Partindo do princípio de que o crescimento do tecido ocorre a partir do repovoamento por células dos tecidos adjacentes à área afetada, a rugosidade radicular passa a ser de extrema importância nesse processo de reparo. A célula que encontra uma superfície "adequada", produz mais fatores de crescimento para quimiotaxia e diferenciação de novas células; além disso, a rugosidade pode influenciar a velocidade de mitose das células que populacionarão a superfície em 
questão ${ }^{23,24}$. A rugosidade ideal da superfície radicular para o reparo não está estabelecida.

Com o intuito de produzir uma superfície radicular viável, o tratamento inicial de doença periodontal é a raspagem e o alisamento radiculares com vários tipos de instrumentos. A função primordial desta instrumentação é a remoção de cálculos aderidos, placa bacteriana e cemento superficial, permeado por toxinas, da superfície radicular. Segundo $\mathrm{Nagy}^{18}$, a relação entre o cálculo e a doença periodontal ainda não estão totalmente estabelecidas, porém a remoção por instrumentação do cálculo supra e sub gengivais é um meio efetivo para a melhorar a saúde do periodonto. Porém a raspagem não é totalmente eficiente e mesmo a mais criteriosa delas com qualquer tipo de instrumento manual ou vibratório deixa sobre a superfície radicular restos de cálculo ainda aderidos 13,30. Além disto, a raspagem causa a formação de "smear-layer" sobre a raiz o que dificulta a adesão, migração e proliferação celular ${ }^{3,12}$.

Faz-se então necessário, para promover melhores condições para as células regeneradoras, o uso de condicionadores químicos sobre a superfície instrumentada, como o ácido cítrico e o EDTA ${ }^{20,28,29}$. $\mathrm{O}$ ácido cítrico age por baixo $\mathrm{pH}$, dissolvendo o "smear layer" e expondo fibras colágenas sobre as superfícies de dentina e de cemento, o que aumenta o número de células aderidas a estas superfícies ${ }^{29}$; além disto, pode dissolver pequenos cálculos sub-clínicos deixados durante a instrumentação ${ }^{23}$. Porém por ter baixo $\mathrm{pH}, \mathrm{o}$ ácido cítrico pode ter ação necrótica sobre os tecidos vizinhos ao defeito periodontal doente ${ }^{4}$. Utilizou-se então o EDTA (ácido etilenodiaminotetracético) para o condicionamento radicular, que age por quelação dos íons cálcio, dissolvendo o "smear layer" e expondo fibras colágenas nas superfícies de dentina e de cemento ${ }^{5}$ sem os malefícios do baixo $\mathrm{pH}$, pois seu $\mathrm{pH}$ é proximo de neutro.

Procurou-se com este trabalho analisar em microscopia eletrônica de varredura, as superfícies radiculares hígidas, contaminadas, e obtidas após a raspagem da raiz com curetas manuais, e após raspagem e condicionamento com ácido cítrico (solução líquida) e com EDTA (solução líquida e gel).

\section{REVISÃO DA LITERATURA}

A busca primordial da terapia periodontal é proporcionar condições físicas, químicas e biológicas à superfície contaminada para um repovoamento por células provenientes dos tecidos adjacentes ao defeito que irão regenerar o periodonto que foi destruído pela doença $^{23}$. Nymam ${ }^{19}$, em 1998 afirma que as toxinas bacterianas presentes no cemento encontram-se na superfície, e uma raspagem leve seguida por uma lavagem é suficiente para descontaminar o cemento alterado. Para a instrumentação mecânica da superfície Jotikasthira, Lie, Leknes ${ }^{15}$ afirmam que, por serem os mais práticos e efetivos, os instrumentos manuais como as curetas e os vibratórios como os ultra-sons, são os mais utilizados. Porém, segundo Blömlof, Blömlof e Lindskog ${ }^{3}$, toda instrumentação deixa sobre a superfície radicular uma camada amorfa denominada "smear layer", que é deletéria a regeneração periodontal pois como afirmado por Blömlof ${ }^{5}$, dificulta a adesão, migração e proliferação celular sobre a superfície. Selvig ${ }^{22}$, Vanheusden ${ }^{29}$ e Rompen ${ }^{21}$ afirmam que após a raspagem e polimento radiculares há a necessidade de um condicionamento químico. Schwartz ${ }^{24}$, em 2000, semeou células "osteoblast-like" sobre superfícies de dentina condicionadas ou não e observou que as células semeadas sobre as superfícies condicionadas estavam melhor aderidas, proliferavam mais e sintetizavam mais proteínas, sugerindo o efeito benéfico do condicionamento. RosaWen ${ }^{20}$, em 1992 e Hawkins $^{12}$, em 1997, relatam que a necessidade de condicionamento está baseada em dois efeitos: remoção do "smear layer" e desmineralização superficial com exposição de fibras colágenas.

Dois produtos são bastante utilizados para este fim: o ácido cítrico e o EDTA. Sterrett, Bankey e Murphy ${ }^{26}$, em 1993 realizaram uma pesquisa para avaliar qual concentração de ácido cítrico é mais efetiva e encontraram os melhores resultados com concentrações entre 25 a 30\%. Vanheusden ${ }^{29}$, em 1999 , realizou um trabalho que avaliou o comportamento de queratinócitos gengivais humanos sobre fragmentos de dentina condicionados com ácido cítrico ou não e observou que a adesão celular foi bem melhor sobre os fragmentos condicionados. Porém, Blömlof e Lindskog ${ }^{4}$, em 1995, encontraram efeitos negativos quanto ao uso do ácido cítrico por seu baixo $\mathrm{pH}$ próximo de 1 , pois este produto causou necrose celular nos tecidos adjacentes e sugerem que seria mais benéfico para a regeneração o uso de um condicionante com pH neutro como o EDTA.

Breschi $^{7}$, comparou o efeito do EDTA quanto a remoção de "smear layer" e exposição de fibras colágenas e encontrou efetividade semelhante assim como Blömlof ${ }^{3}$. Clinicamente, Mayfield ${ }^{17}$, em 1998 experimentou o EDTA em defeitos infra-ósseos maiores ou iguais a $4 \mathrm{~mm}$ e observou que o preenchimento e o ganho de inserção foram maiores com o uso do EDTA do que com o uso do ácido cítrico. 


\section{MATERIAL E MÉTODOS}

Para a realização do estudo proposto, foram utilizados 14 dentes de humanos, unirradiculares, sendo 12 dentes com exodontia indicada por perda de inserção severa nas duas proximais, causada por doença periodontal, e 2 dentes hígidos com exodontia indicada por ortodontia ou dentes impactados.

Após doação dos dentes, pelos pacientes, aprovada pelo comitê de ética da Faculdade de Odontologia de Bauru, foi realizada a exodontia com o cuidado de não tocar nas superfícies radiculares, que seriam utilzadas para as análises deste estudo.

Após a exodontia os dentes foram gentilmente raspados com curetas plásticas para a remoção de restos de tecidos moles aderidos e preparados em 28 corpos de prova como descrito a seguir: a coroa e o terço apical da raiz foram seccionados com discos de carborundum, montados em contra-ângulo e em baixa rotação, sob abundante irrigação de soro fisiológico e descartados. O remanescente radicular, contendo os terços médio e cervical, foram então seccionados no sentido axial vestíbulo-lingual do dente resultando duas metades, ou dois corpos de prova (figura 1).

Após a preparação, os 28 corpos de prova foram divididos aleatoriamente em 6 grupos que receberam os tratamentos como a seguir: grupo 1 - 4 corpos de prova provenientes de dentes hígidos sem tratamento; grupo $2-5$ corpos de prova provenientes de dentes contaminados sem tratamento; grupo 3 - 5 corpos de prova provenientes de dentes contaminados foram raspados com curetas manuais de Gracey $n^{\circ} 5 / 6$ até a lisura superficial; grupo 4 - 5 corpos de prova provenientes de dentes contaminados foram raspados com curetas manuais de Gracey $n^{\circ}$ 5/6 até a lisura superficial + condicionamento com solução líquida de ácido cítrico a $37 \%(\mathrm{pH} 1)$ por 3 minutos; grupo 5 - 5 corpos de prova provenientes de dentes contaminados foram raspados com curetas manuais

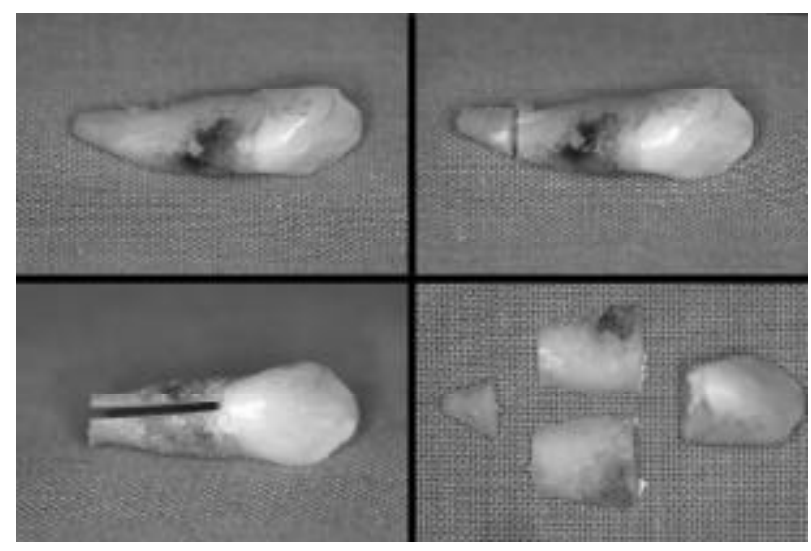

FIGURA 1- Preparação dos corpos de prova de Gracey $n^{\circ}$ 5/6 até a lisura superficial + condicionamento com solução líquida de EDTA a $24 \%$ (pH 7.2) por 3 minutos ; e grupo 6 - 4 corpos de prova provenientes de dentes contaminados foram raspados com curetas manuais de Gracey $n^{\circ}$ 5/6 até a lisura superficial + condicionamento com gel de EDTA a 24\% (pH 7.1) por 3 minutos.

Nos grupos 4 e 5 as soluções foram aplicadas nas superfícies com bolinhas de algodão embebidas na solução por 3 minutos sendo que a bolinha foi trocada a cada minuto. No grupo 6 o gel foi espalhado sobre a superfície com uma espátula e mantido até os três minutos. Após as preparações os corpos de prova foram lavados com soro fisiológico por 1 minuto.

As curetas utilizadas foram de Gracey $n^{\circ} 5 / 6$ (Hufriedy - U.S.A), novas e afiadas após a raspagem de cada corpo de prova com pedras de granulação média (Norton - U.S.A.), conforme orientação do fabricante.

As soluções condicionantes utilizadas neste estudo foram manipuladas em farmácias de manipulação (Pharmácia Specifica - Bauru - Brasil) seguindo as formulações: ácido cítrico: 37 gramas de ácido cítrico anidro diluídos em $100 \mathrm{ml}$ de água destilada com $\mathrm{pH}$ final igual a 1; EDTA líquido: 24 gramas de EDTA tetrasódico diluídos em 100ml de água destilada com pH final igual a 7,2; EDTA gel: 24 gramas de EDTA tetrasódico diluídos em 100ml de gel de carbopol com $\mathrm{pH}$ final igual a 7.1.

Após a desidratação em alcool absoluto os corpos de prova receberam aposição superficial de $10 \mathrm{~mm}$ de ouro para análise em um microscópio eletrônico de varredura (Philips - XL 30 a $20 \mathrm{kV}$ e detector eletro secundário SE).

\section{RESULTADOS}

Grupo 1 - Todos os corpos de prova apresentaram resultados semelhantes: os remanescentes das fibras colágenas do ligamento periodontal aderidas ao cemento mostraram-se como grânulos regulares por toda a superfície. Não se observou áreas de reabsorção cementária ou áreas sem cemento, nem restos de tecido mole aderidos. As trincas presentes, com largura média de 3 a $5 \mathrm{~mm}$, são artefatos de técnica, provenientes da desidratação para análise em microscopia eletrônica de varredura (Figura 2).

Grupo 2: Os corpos de prova mostram massas de um material amorfo, mineralizado, bastante poroso , características do cálculo, sobre uma área de cemento com as mesmas características de cemento normal e áreas de reabsorção cementária (Figura 4). As estruturas circulares da figura 3A são os estágios iniciais da 
formação do cálculo. Em grande aumentos, nas margens do cálculo, pode-se observar a presença de bactérias e a grande porosidade do cálculo (Figura 3B).

Grupo 3 - Em pequenos aumentos (figura 5A) observa-se uma superfície plana e regular, em que é nítida a presença de estrias paralelas provenientes da raspagem com instrumentos manuais. Em aumentos maiores (figura 5B) o aspecto é de uma superfície amorfa e irregular, caracterizando o "smear layer". Não é possível observar, em nenhuma parte dos corpos de prova do grupo 3 , áreas de cemento ou dentina.

Grupo 4 - Neste grupo observa-se que o ácido cítrico foi eficiente na remoção do "smear layer" tanto em áreas de cemento quanto em áreas de dentina. A figura 6A mostra uma área onde o cemento foi removido durante a raspagem e o "smear layer" foi removido da dentina desobstruindo os túbulos dentinários. A figura 6B mostra uma área de cemento descoberta de "smear layer" com fibras colágenas à mostra e na figura $6 \mathrm{C}$ mostra um pequeno cálculo sub clínico parcialmente

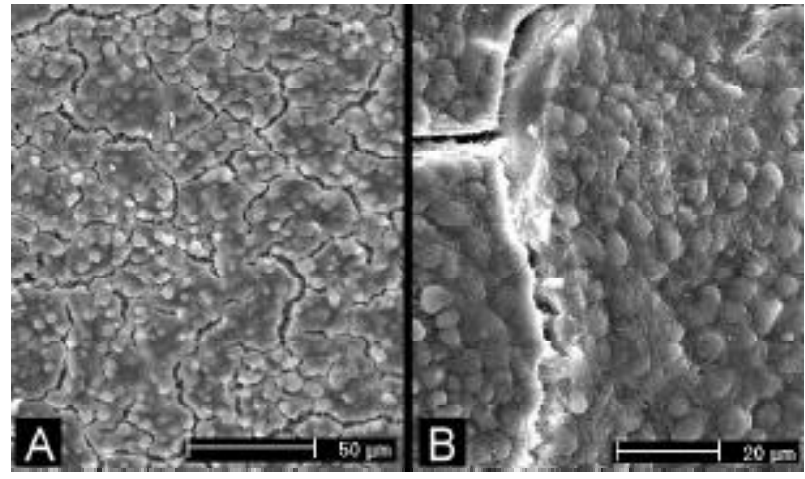

FIGURA 2- grupo 1 - dentes hígidos: A e B: grânulos representando as fibras colágenas rompidas. $(A-$ aumento $400 \mathrm{X}$ e B - aumento 800X)

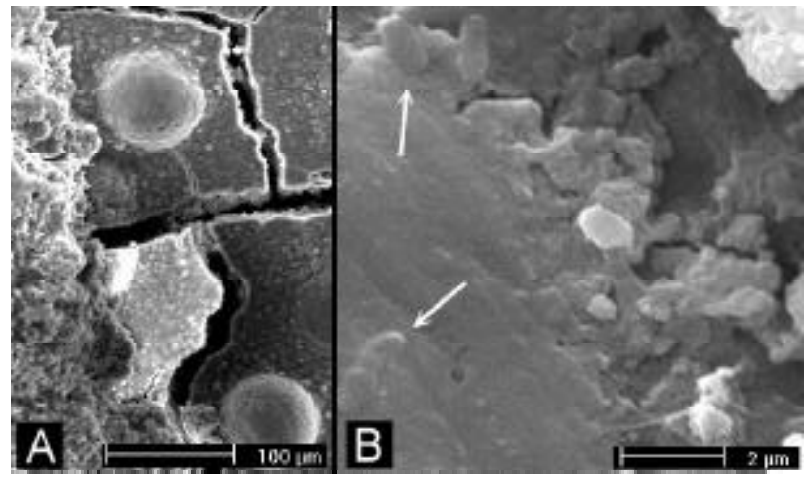

FIGURA 3- grupo 2 - dentes contaminados: A - cálculo bastante poroso; as estruturas circulares são o início de calcificação da placa bacteriana (aumento 200X; B margem do cálculo: presença de bactérias (setas) (aumento 8000X) desmineralizado e dissolvido pela ação do ácido cítrico.

Grupo 5 - As leituras deste grupo mostram que o EDTA solução líquida não foi eficiente na remoção total do "smear layer". Na figura 7A observa-se um túbulo dentinário parcialmente desobstruído e na figura 7B nota-se uma superfície de cemento com o smear recobrindo parcialmente as fibras colágenas e as estrias paralelas deixadas pelas curetas ainda presentes.

Grupo 6 - O EDTA gel conseguiu uma ação condicionante semelhante à do ácido cítrico. Na figura $8 \mathrm{~A}$ observa-se, em grande aumento, um túbulo dentinário totalmente desobstruído e com uma trama de fibras colágenas em seu interior. Na figura 8B, observa-se uma superfície cementária sem a presença de "smear layer" e com as fibras colágenas à mostra, como no cemento normal.

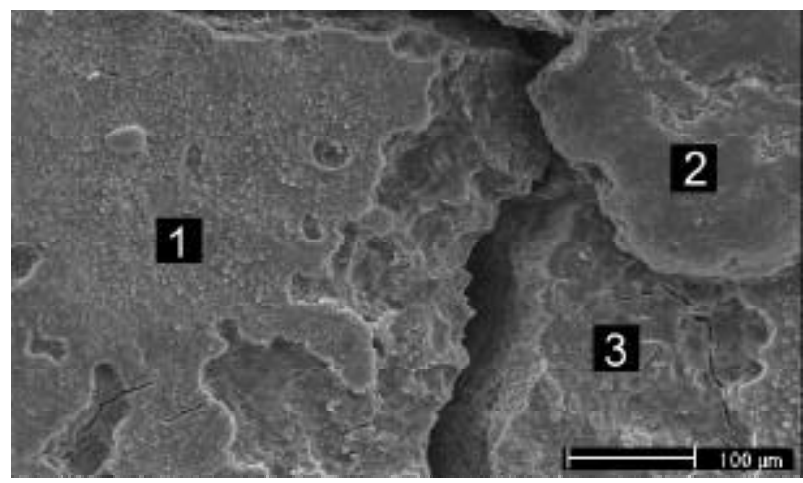

FIGURA 4- grupo 2 - dentes contaminados: 1. cemento aparentemente normal; 2. massa de cálculo, 3. reabsorção cementária (aumento 200X)

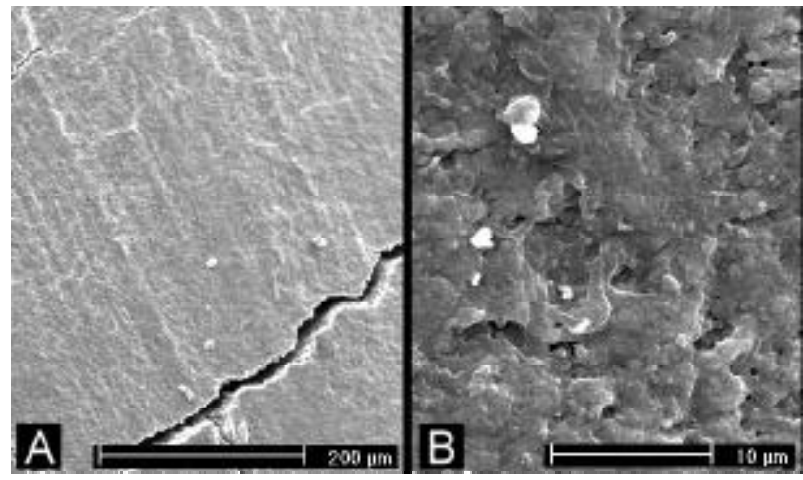

FIGURA 5-grupo 3 - dentes instrumentados: A - superfície plana com estrias paralelas deixadas pela lâmina da cureta (aumento 160X); B - Smear layer (aumento 2500X) 


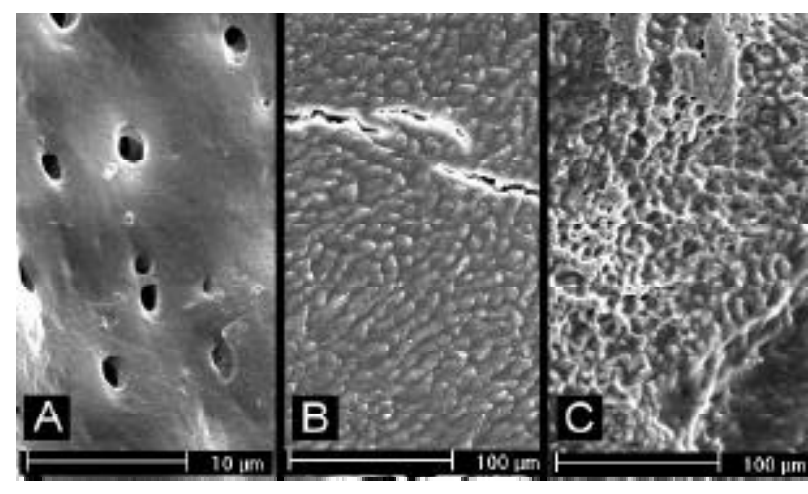

FIGURA 6- grupo 4 - dentes instrumentados e condicionados com ácido cítrico: A - ausência de smear layer e túbulos dentinários desobstruídos (aumento 2500X); $\mathrm{B}$ - smear layer removidos e fibras colágenas à mostra (aumento 350X); C - pequena massa de cálculo parcialmente dissolvida (aumento 300X)

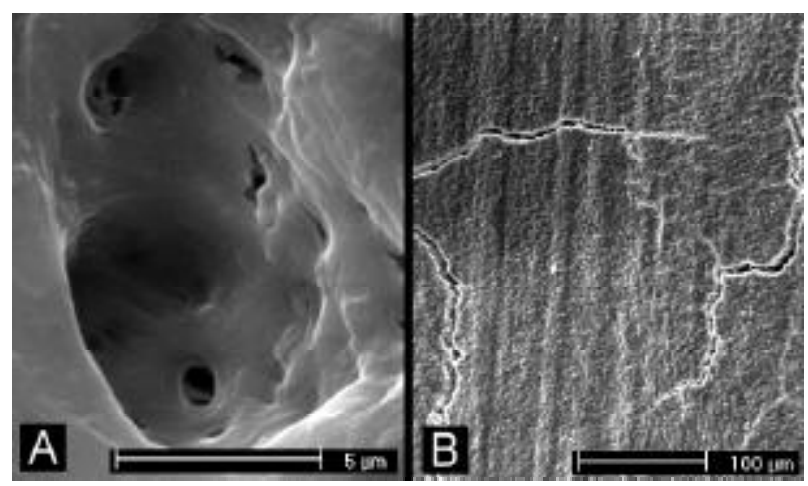

FIGURA 7-grupo 5 - dentes instrumentados e condicionados com EDTA líquido: A - túbulo dentinário parcialmente desobstruído (aumento 6400X); B - remoção parcial do smear e estrias deixadas pela cureta ainda presentes (aumento200X)

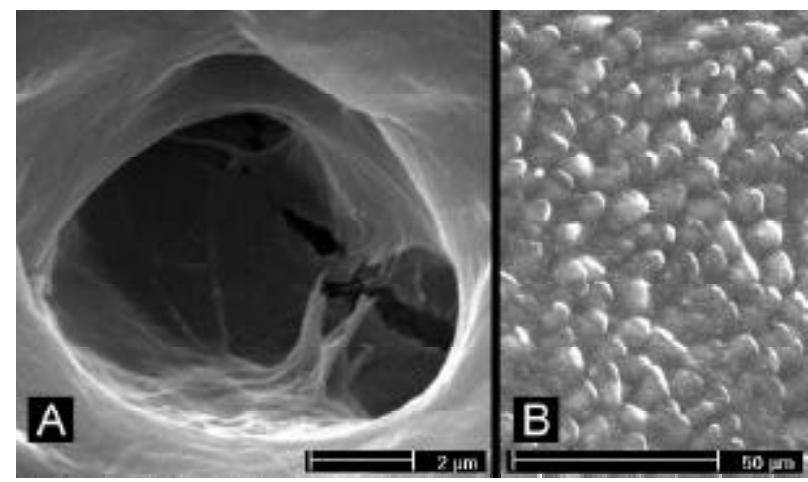

FIGURA 8- grupo 6 - dentes instrumentados e condicionados com EDTA gel: A - túbulo dentinário totalmente desobstruído com fibras colágenas (aumento 8000X); B - smear layer removido e fibras colágenas à mostra (aumento640X)

\section{DISCUSSÃO}

Este estudo analisou e comparou as superfícies hígidas, as superfícies contaminadas e as obtidas após raspagem e condicionamento com ácido cítrico e EDTA. Quanto às superfícies obtidas após a raspagem observou-se que houve a formação de "smear layer" em todos os corpos de prova, concordando com Blömlof ${ }^{3}$, Breschi ${ }^{11}$ e Tanaka ${ }^{27}$. A presença de smear layer traz duas consequiências deletérias: dificulta a adesão, migração e proliferação celular, e segundo Brunette $^{8}$, células aderidas a uma superfície orientamse e migram paralelamente a orientação da rugosidade. Observamos que a raspagem forma na superfície "smear layer" e impresso neste smear estrias paralelas. Se durante o ato de raspagem, executado do ápice para a coroa, são deixadas estrias paralelas neste sentido, podemos hipoteticamente, facilitar a migração de células de tecido mole para o sentido apical, guiadas pelas estrias da superfície aumentando a velocidade de migração epitelial e influenciando a competição de repovoamento da superfície radicular.

Como agentes condicionantes foram utilizados, neste estudo, o ácido cítrico a 37\% (pH1) e o EDTA em duas formas: líquida a $24 \%(\mathrm{pH} 7.2)$ e gel a $24 \%$ (pH 7.1), manipulados em farmácias para termos a certeza das formulações e não mascararmos os resultados com possíveis alterações nas fórmulas vendidas comercialmente.

O ácido cítrico foi aplicado nas superfícies com bolinhas de algodão embebidas na solução por três minutos como preconizado por Sterett ${ }^{26}$, RosaWen $^{20} \mathrm{e}$ Hawkins $^{12}$, e pudemos observar que este condicionante foi efetivo na remoção do "smear layer" tanto sobre cemento quanto sobre a dentina e ainda observou-se outro efeito positivo: o ácido desmineralizou parcialmente um pequeno cálculo sub-clínico deixado na raspagem. Sabe-se que a raspagem, por mais criteriosa que seja, não é perfeita, e se o condicionamento remove estes pequenos cálculos que foram deixados, em concordância com Tanaka ${ }^{27}$ podemos afirmar que este é outro benefício do condicionamento radicular.

O EDTA na forma líquida não foi eficiente na remoção total do "smear layer", discordando dos trabalho de Blömlof ${ }^{2}$ e Breschi ${ }^{7}$, pois ainda havia este material cobrindo parcialmente as fibras do cemento e os túbulos dentinários; já o EDTA gel foi tão eficiente na remoção do smear layer e exposição de fibras colágenas quanto o ácido cítrico.

Portanto, dos tratamentos de superfícies radiculares mais comumente utilizados e que foram simulados neste estudo observa-se que a instrumentação é 
necessária para remoção de grandes massas de cálculo e de placa bacteriana, no entanto é ineficiente na criação de uma superfície adequada para a reparação do periodonto. Utiliza-se, então, como complementação à raspagem, o condicionamento químico da raiz, que, quando efetivo, produz uma superfície muito próxima fisicamente à superfícies hígidas, mas não com a mesma capacidade de induzir a formação de novo periodonto. A busca por uma superfície "ideal" continua atualmente com a associação de instrumentação, condicionantes e proteínas indutoras da formação de novos tecidos como a amelogenina ${ }^{21}$.

\section{ABSTRACT}

The most benefic root surface for periodontal regeneration has not been known. Looking for this surface this study used 14 human teeth prepared as testing corpus and treated with scaling and conditioning with citric acid and EDTA, and analysed in scanning electron microscopy. The health teeth surfaces showed regular grains representing broken periodontal ligament fibers by exodontics. The contaminated surfaces showed calculus masses, very porous, and resorption areas. When scalled with hand curettes the surfaces was covered by smear layer. The citric acid conditioning was efficient on smear layer removal, as well as the EDTA gel, and the EDTA liquid solution was not efficient on smear removal.

UNITERMS: Root scalling; acid conditioning; citric acid; EDTA

\section{AGRADECIMENTOS}

Ao Prof. Dr. Waldemar Monteiro, pesquisador senior do IPEN, por abrir as portas deste instituto para que pudessemos realizar as análises em microscopia eletrônica de varredura

Ao Prof. Dr. Antonio Carlos Marconi Stipp, pela amistosa e relevante colaboração na análise das leituras de microscopia deste trabalho.

\section{REFERÊNCIAS BIBLIOGRÁFICAS}

1- Bergeholtz A, Babay N. Scanning electron microscopy of the root surface texture of extrated periodontally diseased teeth following various etching and chelating regimens. Int J Perio Rest Dent 1998; 18(2): 171-9.
2- Blomlöf JPS, Blomlöf LB, Lindskog SF. Effect of different concentrations of EDTA on smear removal and collagen exposure in periodontally-affected root surfaces. J Clin Periodont 1997; 24 (8): 534-7.

3- Blomlöf JPS, Blomlöf LB, Lindskog SF. Smear layer formed by diferent root planing modalities and it's removal by ethylenediaminetetracetic acid gel preparation. Int J Perio Rest Dent 1997; 17(3): 243-9.

4- Blomlöf JPS, Lindskog SF. Periodontal tissue-vitality after different etching modalities. J Clin Periodont 1995; 22: 464-8.

5- Blomlöf JPS. Root cementum appearance in healthy monkeys and periodontitis-prone pacients after different etching modalities. J Clin Periodont 1996; 23(1): 12-8.

6- Blomlöf JPS. A new concept for etching in restorative dentistry. Int J Perio Rest Dent 1999; 19(1):30-5.

7- Breschi L. Field emission in-lens SEM study of enamel and dentin. J Biomed Mater Res 1999; 46(3): 315-3.

8- Brunette, DM. The effect of surface topography on cell migration and adhesion. In: Ratner BD. Surface characterization of biomaterials. C. 1988, Elsevier. p.200-17.

9- Bye FL, Ghilzon RS, Caffesse RG. Root surface roughness after the use os different modes os instrumentation. Int J Perio Rest Dent 1986; 5: 36-7.

10- Chaves E. The effect of citric acid aplicattion on periodontally involved root surfaces. II. An in vitro scanning electron microscopic study. Int J Perio Rest Dent 1993; 13(2): 188-6.

11- Cugini MA. The effect of scaling and root planning on the clinical and microbiological parameters of periodontal diseases: 12 month results. J Clin Periodont 2000; 27(1): 30-6.

12- Hawkins C, Sterrett JD, Russel C. Citric acid demineralization of cementum and dentin: the effect of the storage medium. J Clin Periodont 1997; 24(4): 264-71.

13- Huerzeler MB. The effectiveness of diferent root debridement modalities in open flap surgery. J Clin Periodont 1998; 25(3): 202-8.

14- Izik AG. A comparative scanning electron microscopic study on the characteristics of demineralized dentin root surface using diferrent tetracycline $\mathrm{HCl}$ concentrations and application times. J Periodontol 2000; 71(2): 219-25.

15- Jotikasthira NE, Lie T, Leknes KN. Comparative in vitro studies of sonic, ultrasonic and reciprocating scaling instruments. J Clin Periodont 1992; 19: 560-9.

16- Lafferty TA. Comparative SEM study on the effect of acid etching with tetracycline $\mathrm{HCl}$ or citric acid on intrumented periodontally-involved humam root surfaces. J Periodontol 1993; 64: 689-93.

17- Mayfield L. Root conditioning using EDTA gel as an adjunct to surgical therapy for the treatment of intraosseous periodontal defects. J Clin Periodont 1998; 25(9): 707-14. 
18- Nagy, RJ. The effect of a single course of a calculus-softening scalling and root planing gel. J Periodontol 1998; 69: 806-11.

19- Nyman S. Role of "diseased" root cementum in healing following treatment of periodontal disease. A clinical study. J Clin Periodont 1998; 15: 464-8.

20- RosaWen C. In vitro effects of citric acid application techniques on dentin surfaces. J Periodontol 1992; 63(11): 883-9.

21- Rompen EH, Goffinet GH, Nusgens B. Human periodontal ligament fibroblast behavior on chemically conditioned dentine. An in vitro study. J Periodontol 1999; 70(10): 1144-52.

22- Selvig D. Does roort surface conditioning with citric acid delay healing? J Clin Periodont 1996; 23(2): 119-7.

23- Schwartz Z.. Underlying mechanisms at the bone-surface interface during regeneration. J Period Res 1997; 32: 166-71.

24- Schwartz Z.. Osteoblast proliferation and differentiation on dentin slices are modulated by pretreatment of the surface with tetracycline or osteoclasts. J Periodontol 2000; 71: 581-7.

25- Sterrett JD, Murphy HJ. Citric acid burnishing of dentinal root surfaces. J Clin Period 1989; 16: 98-104.

26- Sterrett JD, Bankey T, Murphy HJ. Dentin demineralization. The effects of citric acid concentrations and application time. J Clin Periodont 1993; 20: 366-70.

27- Tanaka K., O'Leary TJ, Kafrawy AH. The effect of citric acid on retained plaque and calculus. A short communication. J Periodontol 1989; 60(2): 81-3.

28- Wang H. Effect of root conditioning on periodontal wound healing with and without guided tissue regeneration: a pilot study. I. Histologic evaluation. Int J Perio Rest Dent 1993; 13(6): 55160 .

29- Vanheusden AJ. In vitro stimulation of human gingival epithelial cell attachment to dentin by surface conditioning. J Periodontol 1999; 70(6): 594-603.

30- Yukna RA. Clinical evaluation of the speed and effectiveness of subgingival calculus removal on single-rooted teeth with diamond-coated ultrasonic tips. J Periodontol 1997; 68(5): 43642 .

Autor Correspondente:

Fabio V. R. Bastos Neto

Rua Gabriel de Lara, 425

Brooklin - São Paulo / SP

CEP 04582-050

Fone: 1150931469

Fax: 1150413557

e-mail: bastosneto@terra.com.br 